\title{
Paediatric terminology in the Australian health and health- education context: a systematic review
}

1 RAMONA CLARK | MELISSA LOCKE | ANDREA BIALOCERKOWSKI

2 Menzies Health Institute Queensland, Griffith University, Gold Coast, Old, Australia.

Correspondence to Ramona Clark at Menzies Health Institute Queensland, c/o School of Allied Health Sciences, Griffith University, Gold Coast, Qld 4222, Australia. E-mail: Ramona.Clark2@ griffithuni.edu.au

\section{PUBLICATION DATA}

Accepted for publication 16th April 2015. Published online

\section{ABBREVIATIONS}

NICHD Eunice Kennedy Shriver National Institute of Child Health and Human Development
AIM This study aimed to identify paediatric terminology used in the Australian health and health-education context, propose a standardized framework for Australian use, and compare it with a US-based framework.

METHOD Australian health and health-education websites were systematically searched using a novel hierarchical domain-specific search strategy to identify grey literature containing paediatric terminology. Webpages published from 2009 to February 2014, with a '.gov.au' or '.edu.au' domain and no advertising, were included. Paediatric terms were analysed with power-law distributions. Age definitions were grouped using a chi squared test automatic interaction detection analysis $(p<0.05)$.

RESULTS In total, 34 paediatric terms and 197 unique age definitions were identified in 613 webpages. Terms displayed a language distribution, although definitions had semantic and lexical ambiguity. Age definitions were divided into four statistically different groups $(F=245.3, p<0.001)$. Four paediatric terms with distinct age definitions were proposed based on Australian data: 'infant: 0 to $<1$ year', 'early childhood: 1 year to $<5$ years', 'child: 5 years to $<13$ years', and 'young person: 13 years to $<22$ years'. These recommendations were broader than the US-based comparison.

INTERPRETATION This is a starting point for standardizing Australian paediatric terminology, and a method for exploring paediatric terminology in other countries.
Paediatric terms with overlapping age ranges from birth to adulthood are used interchangeably throughout the world, with variability both within and between nations. ${ }^{1-4}$ In Australia, there are no universally accepted paediatric definitions within health and health-education contexts. ${ }^{1,4,5}$ Australia's Macquarie Dictionary Online defines 'paediatrics' as the study and treatment of children, ${ }^{6}$ but does not define the term 'child'. The definition of the term 'child' may include the relationship to their parents or the transitional age range before adulthood. ${ }^{5,6}$ This may add to confusion. 'Child' is defined as 'a baby or infant' or as a young person determined by statute to be 'less than 17' or 'under 18 or 21 years' in Australian law. ${ }^{6}$ Age of consent, and health-care access and eligibility may differ in children and young people owing to biological, developmental, or psychosocial differences, ${ }^{2}$ and by geographical location. ${ }^{7} \mathrm{~A}$ consenting young person, parent, or carer may access universal child health services provided in Australia within a primary health-care model. ${ }^{8}$ These services can be accessed directly or by referral, often by a general practitioner. ${ }^{8}$ Consent refers to a young person having adequate maturity and mental capacity with a legal recognition of competence with no set age. ${ }^{7,9}$ Age of legal consent often ranges from 14 to 18 years, depending on Australian federal, state, and territory jurisdictions, ${ }^{7,9,10}$ and may be defined using different paediatric terms. Current paediatric term variability has thus created confusion throughout the health-care setting. ${ }^{7,9,11,12}$

Consistent definitions are required to strengthen the communication between departments, facilities, and families. ${ }^{13-15}$ Chronological age groupings for paediatric terms allow health practitioners, young people, parents, and carers to classify an individual easily, without additional assessments, for health-care access and eligibility. ${ }^{2}$ The internet is often the first source parents, carers, and young people will refer to when searching for information about child development or health-care eligibility and access. ${ }^{14,16-18}$ Young people are particularly vulnerable to ambiguous terminology, both because of an increased use of the internet for health information ${ }^{16}$ and a reduced ability to obtain relevant information from websites. ${ }^{17}$ Personally Controlled Electronic Health Records allow health practitioners, parents, and young people to view and share health information with the use of a standard terminology. However, the Systematised Nomenclature of MedicineClinical Terms -Australia dataset used in the personally controlled electronic health records lacks clear age definitions for paediatric terms. Confusion about age eligibility 
requirements caused by ambiguous paediatric terms could restrict access and delivery of child health services. ${ }^{15,16,19,20}$

To facilitate the consistent use of paediatric terms, the US Eunice Kennedy Shriver National Institute of Child Health and Human Development (NICHD) developed a framework to consolidate paediatric terms mapped to medical terminology datasets, including the Systematised Nomenclature of Medicine-Clinical Terms. This framework has been proposed as a requirement for interpreting and sharing research and education resources within the USA and internationally. ${ }^{2,4,21}$ However, differences exist between the US and Australia's legal age, health-care delivery, and education systems. ${ }^{22}$ No clear definitions of paediatric terms used within Australia's health and healtheducation systems have been identified in the literature, and there has been no documented comparison with the NICHD's proposed framework. Williams et al. ${ }^{2}$ proposed that the first step towards standardization of paediatric terminology is to identify terms currently used nationally before comparing them with international definitions.

The aims of this study were (1) to systematically identify paediatric terms and definitions used in publically accessible Australian health and health-education sources, (2) to compare paediatric terms and definitions and contrast these with the NICHD definitions, and (3) to consolidate paediatric terminology and definitions to suggest a framework for use in the Australian health and health-education context.

\section{METHOD}

A systematic review was undertaken to address the study aims. Grey literature accessed from websites in the form of government and education reports and documents, fact sheets, and policy statements, ${ }^{23,24}$ in addition to other publically accessible website sources, were the focus of this study.

\section{Search terms}

Recommendations from previous studies ${ }^{25-27}$ were combined to create a comprehensive and reproducible search strategy to identify paediatric terminology contained in over 300 publically accessible Australian health and healtheducation websites. The paediatric-specific search terms used for this study are presented in Table I.

\section{Search strategy}

The internet was searched from 18 to 28 February 2014 to identify paediatric terms and their definitions used in the Australian health and health-education context. The search strategy is described in Figure 1. Search engines and databases were not used to identify data, as they do not adequately search for these types of document, with the exception of Journal Citation Reports, which were used to access Australian journals. ${ }^{28}$ Websites were included if they met critical appraisal guidelines: ${ }^{29-32}$ (1) website was a non-commercial Australian site identified by 'gov.au' or ‘.edu.au' domains, ${ }^{30,31}$ not excluding Australia's Macquarie

\section{What this paper adds}

- A novel search strategy identified Australian paediatric terminology from health and health-education websites.

- Ambiguous paediatric terminology was found.

- Four paediatric terms with distinct age ranges addressed this ambiguity.

- Australian age ranges were broader than the US-based comparison.

Dictionary Online; ${ }^{6}(2)$ webpage was modified or updated within 5 years of the search date $;^{30,31}$ (3) webpage contained no advertising. ${ }^{30}$

Websites were divided into five categories to facilitate systematic searching of linked webpages: (1) federal, state, and territory government, (2) health practitioners, (3) hospitals and health care, (4) Australian journals-their scope and guidelines, (5) dictionaries and national statistics. Webpages that did not contain information pertaining to health or health education were excluded from this study. Paediatric terms were identified from webpages using the internet browser's 'find' function to systematically search for a group of terms (contained in Table I). Definitions of all identified terms were searched by reviewing surrounding paragraphs. An additional search using the terms 'aged' and 'years' was performed when definitions were not found through reviewing paragraphs. Webpages accessed via a click-through were reviewed using the same strategy. If no paediatric terms or associated definitions were found at a tertiary webpage level, the search was considered exhausted. A glossary of terms underpinning the internet search method is provided in Table II. Specific search strategies for each website category are listed in Appendix S1 (online supporting information).

\section{Data handling and analyses Data extraction}

The three authors agreed upon website selection. One author (RC) extracted paediatric terms and associated definitions from identified webpages, noting the webpage hierarchy level and geographical origin. Spelling variations and plural terms were recorded once per webpage before being truncated to a single term. Grouped terms were separated into individual terms and definitions were separated into a single term with a single minimum and maximum age defi-

\begin{tabular}{l}
\hline Table I: Paediatric-specific search terms ${ }^{\text {a }}$ \\
\hline Adolescen \\
\hline Bab \\
Child \\
Early year \\
Infan \\
Junior \\
Juvenile \\
Kid \\
Neonat \\
Newborn \\
Paediatric \\
Pediatric
\end{tabular}

${ }^{a}$ Expanded search terms were used (e.g. neonat=neonate, neonates, neonatal, neonatology, neonatologist). 


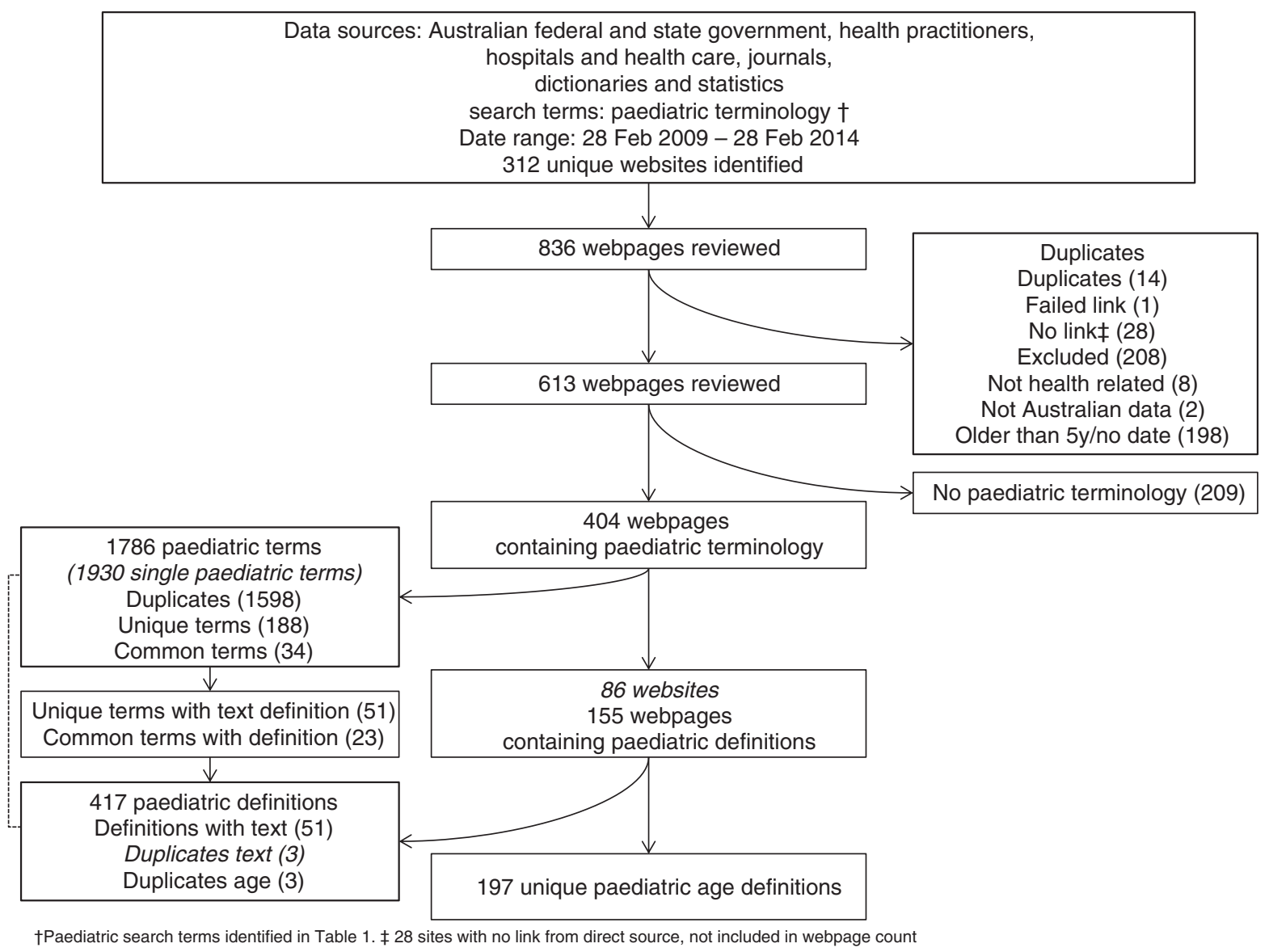

Figure 1: Systematic search strategy used to identify paediatric terminology and associated age definitions.

Table II: Glossary of terms underpinning the search methods

A set of related webpages served from a single

Website web domain (e.g. gov.au)

Source website An overarching website likely to contain links to similar websites of relevant information or key webpages (e.g. Australia.gov.au

Primary A direct link accessed via the source website (e.g. website Health.gov.au)

Secondary A direct link accessed via the primary website

website

Webpage

Homepage

Primary

webpages

Secondary

webpages

Tertiary

webpages

Click-through

A hierarchy of documents accessed by a clickthrough from a website (e.g. Australia.gov.au/ about us) Initial level of webpage hierarchy (i.e. no links) A webpage accessed via one-click through from the homepage (e.g. Australia.gov.au/about) A webpage accessed via two click-throughs (e.g. Australia.gov.au/people/children)

A webpage accessed via three or more clickthroughs

Process of clicking on an internal link by using the mouse to click on a button, tab, or embedded URL

nition for analysis (e.g. 'children and adolescents from 6 to $18 \mathrm{y}$ ' became 'child=from $6 y$ ', 'adolescent=up to $18 \mathrm{y}$ '). Terms were separated into three groups: 'terms only', 'terms with text definition(s)', and 'terms with age definition(s)'.

\section{Data analyses}

Paediatric terminology. The Statistical Package for the Social Sciences version 22 (IBM SPSS Statistics, Armonk, NY, USA) was used for all analyses. Power-law distributions were used to summarize the frequency of specific paediatric terminology identified within the Australian health and health-education context. The type-token ratio was calculated as an index of lexical diversity by dividing the number of unique terms (type) by the total number of terms (token). ${ }^{33}$ Kalankesh et al. ${ }^{33}$ suggested an appropriate sample for language analysis has a type-token ratio of less than 0.1 . Terms containing an age definition were subjected to further analysis.

Paediatric definitions. Minimum and maximum age definition(s) were analysed using descriptive statistics. Unique definitions were calculated by removing duplicate combinations of terms and age ranges. Ambiguity was calculated by measuring semantic differences (same terms with different definitions) and lexical differences (different terms with the same definition). A decision-tree analysis, using non-parametric chi squared test automatic interaction detection, 
was used to group paediatric terms with homogenous age ranges $(p<0.05)$. Categories were then re-analysed until they could not be further divided into significantly different $(p<0.05)$ subcategories or would contain less than $5 \%$ of the total terms and age definitions $(n=30)$ as recommended by Ritschard. ${ }^{34}$ A Bonferroni adjustment was used to maintain a $p<0.05$ significance, with a threshold of significance determined based on the number of subdivisions.

\section{RESULTS}

The search strategy identified 312 unique websites and reviewed 613 unique webpages that met the inclusion criteria (Fig. 1). There was an unequal geographical distribution of webpages, with age definitions predominantly published in the Australian Capital Territory ( $n=146$, $39.9 \%)$. Larger distributions were found in New South Wales $(n=65,17.8 \%)$, Victoria $(n=45,12.3 \%)$, and Western Australia $(n=43,11.7 \%)$, with the remainder divided between Queensland ( $n=22,6.0 \%)$, South Australia $(n=17$, $4.6 \%)$, Northern Territory $(n=13,3.6 \%)$, and Tasmania $(n=13,3.6 \%)$. There were also two definitions from external Medical Subject Heading sites $(n=2,0.5 \%)$. Tertiary webpages contained nearly half $(46.4 \%)$ of all paediatric age definitions. The remaining definitions were distributed between primary webpages $(26.5 \%)$, secondary webpages $(19.6 \%)$, and homepages $(7.5 \%)$.

\section{Paediatric terminology}

Four hundred and four (65.9\%) webpages contained paediatric terminology, with 188 unique terms grouped into 34 common paediatric terms. The Pareto distribution of paediatric terms displayed in Figure 2 shows that the top 21\% of terms ('child', 'young person', 'paediatric', 'youth', 'adolescent', 'infant', and 'baby') accounted for $72 \%$ of cumulated terms with a type-token ratio of 0.012 . Nearly onethird of cumulated terms comprised 'Child'.

\section{Paediatric definitions}

Of all identified terms, $23.9 \%$ were defined. When reduced to common terms, $73.5 \%$ had a definition. Paediatric defi-

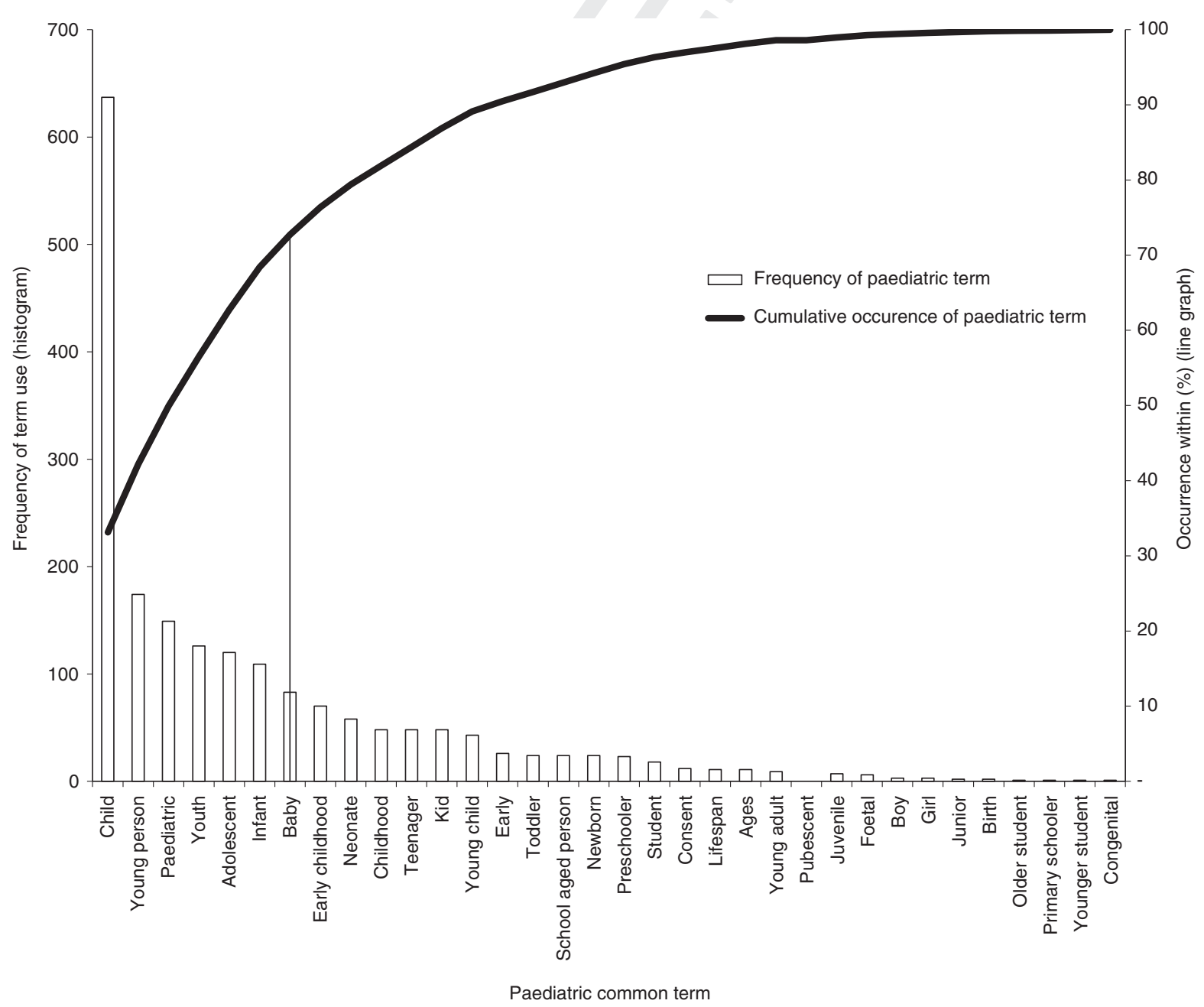

Figure 2: Paediatric term frequency and cumulative percentage of paediatric term occurrence $(n=1786)$. 
nitions were found in 148 unique webpages (24.1\%), and comprised 46 (18.9\%) unique text definitions and 197 $(81.1 \%)$ unique age definitions (Fig. 1). Semantic ambiguity was found, with 19 out of 23 common terms having more than one definition. Lexical ambiguity was found, with 129 definitions having more than one common term. 'Junior' was the only common term that had a single unique definition 'from 4 years up to 6 years'. The decision-tree analysis identified four groups of paediatric terms that were significantly different with respect to mean age ( $F=245.3$, adjusted $p<0.001$ ), as determined by the Bonferroni-adjusted threshold of significance $(p<0.013)$ (Fig. 3). Mean ages (SD) for each of the identified groups were 10 months (SD 1y), 3 years 1 month (SD 2y 6mo), 7 years 4 months (SD 6y), and 16 years 10 months (SD 5y 1mo). The SDs demonstrated that age ranges in group 3 displayed the largest amount of overlap. Ages in group 3 overlapped with each of the other three groups and contained the largest proportion of definitions $(n=267$ [44.7\%]).

\section{DISCUSSION}

This study used a novel approach to systematically identify, review, and synthesize information contained in publically accessible grey literature and websites within health and health-education contexts. The use of a hierarchical domain-specific search strategy increased the repeatability of a search and reduced bias towards selecting popular webpages. ${ }^{35}$ Search strategies using external or internal search engines (e.g. Google) use algorithms based on dynamic user interaction to determine a webpage's popularity. ${ }^{36-38}$ High numbers of irrelevant hits often result in screening only the most popular webpages, ${ }^{31,37}$ which have no direct relationship to webpage credibility. ${ }^{28}$ Webpage hierarchies allow effective internal navigation of large websites such as government and education domains. ${ }^{39,40}$ Government and education domains require federal approval, explaining the increased skew of webpages originating from the Australian Capital Territory. Despite using a hierarchical search strategy, a paucity of paediatric definitions was found compared with paediatric terms, with most buried deep within a website's hierarchy. Deep hierarchies can lead to undiscoverable content. ${ }^{17,40}$ This may affect patient care if paediatric terms are misinterpreted without a definition. ${ }^{20}$ Paediatric terms should therefore be defined with an age range and consistently used across health and health-education contexts. This is the minimum recommendation before a standard paediatric terminology can be developed.

A standard paediatric terminology for the Australian health and health-education contexts is proposed using language distributions and cluster analysis of paediatric terms
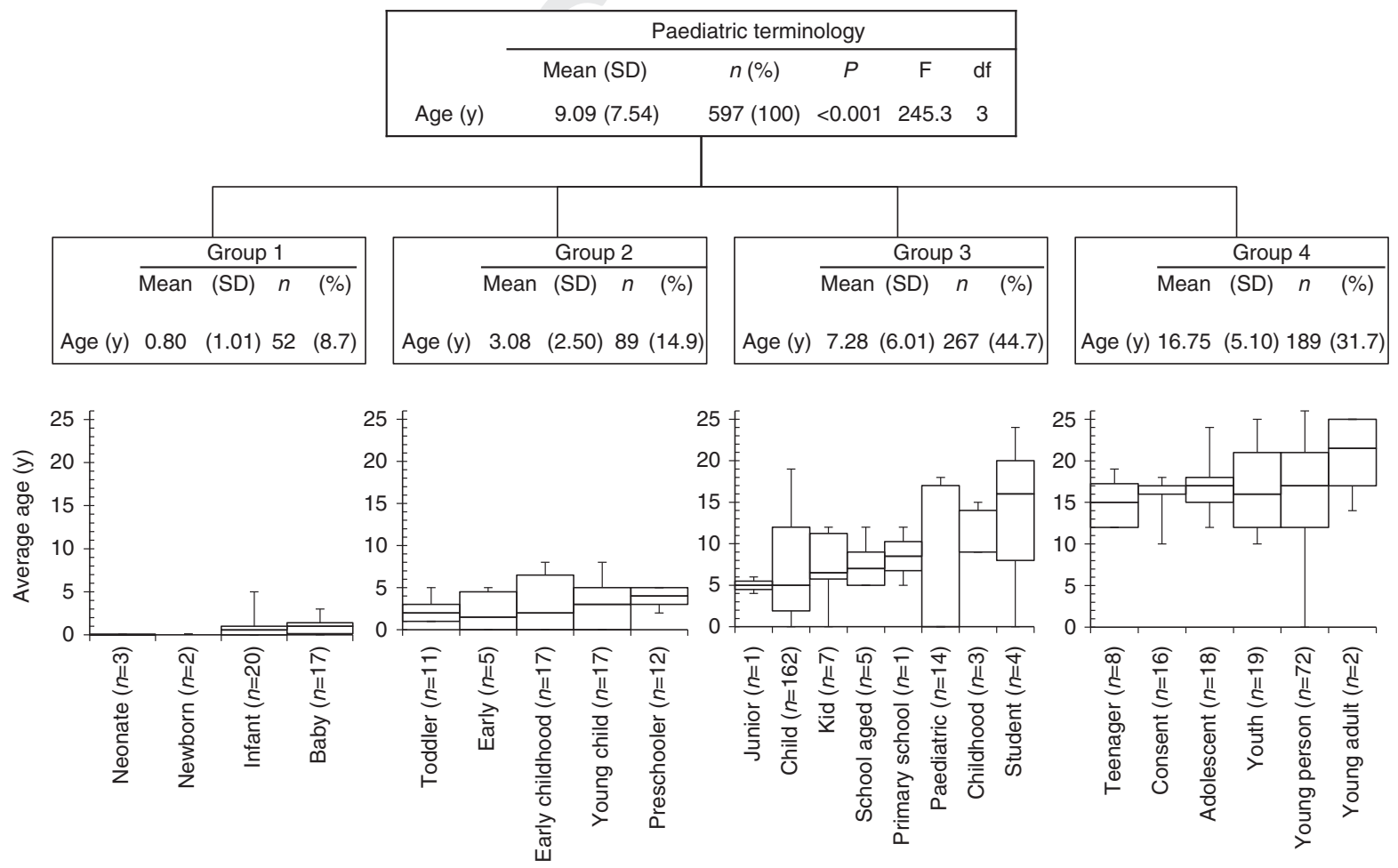

Paediatric term

The box displays the interquartile range of ages with the bottom line denoting the lower $25 \%$ and the top line the upper $75 \%$. The middle line is the median age.

The error bars (whiskers) are the minimum and maximum age recorded for the corresponding paediatric term.

Figure 3: Paediatric term classification based on homogenous age definitions. 
and age-range definitions. By viewing paediatric terms as a specialized vocabulary, a power law analysed language and found seven $(21 \%)$ of the identified paediatric terms accounted for the majority of identified terms. This was less skewed than typical 80/20 Pareto distributions, ${ }^{41}$ which may highlight the interchangeable use of terms. The low type-token ratio in this study suggested an appropriate sample for language analysis. ${ }^{33}$ Similar datasets from electronic health records used by general practitioners in England have viewed terms as a language distribution. ${ }^{33,41}$ Language distributions can assist in selecting paediatric terms to develop standard paediatric terminology when used in combination with an age definition.

Age ranges did not explicitly demarcate a third of the paediatric definitions found in this study. Defining paediatric terms by chronological age, where able, will reduce confusion about health-care access and information interpretation by stakeholders, such as health practitioners, young people, parents, and carers. ${ }^{1,2}$ Eliminating semantic and lexical ambiguities will reduce the confusion further. ${ }^{19,20,42}$ Semantic ambiguity was addressed first, using a chi squared test automatic interaction detection analysis decision-tree analysis, to statistically group homogenous age definitions. Ages were clustered into four groups to create a single calculated mean and age range using the SD. Chi squared test automatic interaction detection analysis has previously been used in health-care research to determine characteristics of patients for medical attendance $^{43}$ and trauma outcomes. ${ }^{44}$ Lexical ambiguity was then addressed by selecting a representative term from the Pareto distribution for each of the groups 1-4: 'infant', 'early childhood', 'child', and 'young person' (see column 1 in Table III).

Groups from the chi squared test automatic interaction detection analysis lacked distinct age ranges (mean and SD) required for clear terminology. ${ }^{1}$ This is consistent with Contopoulos-Ioannidis et al., ${ }^{3}$ who identified extensive overlap of paediatric age groups within recent publications of paediatric randomized control studies. Greater variance was found in older age groups of this study, which may be explained by differences in determining consensual age between Australian states and territories. ${ }^{7,9,45,46}$ Ages

\begin{tabular}{|c|c|c|c|}
\hline \multicolumn{2}{|l|}{ Current study } & \multicolumn{2}{|c|}{$\mathrm{NICHD}$} \\
\hline Term & Definition & Term & Definition \\
\hline Infant & 0 to $<1 y$ & Infancy stage & Birth-12mo \\
\hline Early childhood & 1 to $<5 y$ & $\begin{array}{l}\text { Toddler stage } \\
\text { Early childhood }\end{array}$ & $\begin{array}{l}13 m o-2 y \\
2-5 y\end{array}$ \\
\hline Child & 5 to $<13 y$ & Middle childhood & $6-11 y$ \\
\hline Young person & 13 to $<22 y$ & $\begin{array}{l}\text { Early adolescence } \\
\text { Late adolescence }\end{array}$ & $\begin{array}{l}12-18 y \\
19-21 y\end{array}$ \\
\hline
\end{tabular}

NICHD, Eunice Kennedy Shriver National Institute of Child Health and Human Development. calculated for each group were also not in whole years. Defining maximum age ranges in whole years up to the birthday of the subsequent minimum age (e.g. 5 to $<13 \mathrm{y}$ ) would assist in preventing confusion about age inclusion. ${ }^{11}$ Distinct and inclusive age ranges for each of the four groups were proposed by manually adjusting the SDs to obtain age ranges in whole numbers, while maintaining a mean age close to the chi squared test automatic interaction detection analysis calculated mean. Consensus was gained between the researchers to eliminate semantic ambiguity and derive the final age-range definitions for each of the groups: 'infant: 0 to $<1$ year', 'early childhood: 1 year to $<5$ years', 'child: 5 years to $<13$ years', 'young person: 13 years to $<22$ years' (see column 2 in Table III).

The four age groups were then compared with the framework proposed by the NICHD (Table III). The groups identified within this study had broader age ranges. 'Infant' was the most consistent group, which coincided with the NICHD's 'Infancy stage' from 0 years to 12 months or 1 year. This study's 'Early childhood' group encompassed both the NICHD's 'toddler' and 'early childhood' groups. The minimum age range for 'Child' is lower than the NICHD's comparable 'middle childhood' minimum age. This chronological period parallels the Australian education system, coinciding with start of school. ${ }^{47}$ The 'Child' group also included definitions for the term 'paediatric', which appeared to consistently represent a broadly used term that included individuals from 0 years (birth) until 18 years (the Australian legal age). This may support the use of 'paediatric' as a separate umbrella term to encompass all individuals who are not yet adults ( 0 to $<18 \mathrm{y})$. The maximum age of $<22$ years for 'Young person' is older than the national legal age in Australia and extends beyond the NICHD framework. The NICHD's framework is recommended as a starting point for the standardization of paediatric terminology. ${ }^{2,4}$ Comparison with the NICHD's framework will allow the identification of unique population differences. The unique differences identified within this study support further investigation of paediatric terminology within the Australian health and health-education context, as well as in other geographical areas, to inform the development of an international set of paediatric terms and definitions. As a first stage, we recommend the four proposed terms, with the broader age definitions identified for use in the Australian health and health-education context (Table III).

The age groupings within this study are representative of ages most frequently contained in Australian health and health-education grey literature and websites. Consensus is required to determine if the maximum age range for 'young person' should extend beyond the Australian legal age of 18 years. Care must be taken to ensure these definitions are also the most clinically appropriate. ${ }^{2,3,11}$ Williams et al. $^{2}$ supported chronological age groupings for paediatric definitions as a proxy for biological, developmental, or psychological stages because of the ease in which health practitioners, parents, carers, and young people can classify 
individuals. However, it is acknowledged that specific areas of paediatric research and clinical practice may require narrower age ranges, depending on clinical rationale. For example, 'neonates', who are typically defined as being from 0 to 28 days, could be a subgroup of 'infants' owing to well-documented specific clinical needs. ${ }^{2,3}$ Researchers and clinicians working with children in a specific context may also require additional classification through assessment of biological or psychological markers, ${ }^{5}$ and researchers may require additional criteria to determine an individual's capacity to consent irrespective of age. ${ }^{7} \mathrm{Wil}-$ liams et al. ${ }^{2}$ suggested that the next step towards standardization of international paediatric terminology is to gain consensus from experts about physiological, cognitive, and developmental differences in paediatric individuals.

Knowledge translation activities are required both to inform health practitioners, researchers, and policy makers, particularly in government, about the inconsistencies of paediatric terminology identified within documents and to initiate a change towards standardization. A governance model, for example as described by Kahn et al., ${ }^{1}$ may underpin future work in implementing standard paediatric terminology, such as that proposed in this study. Using consistent paediatric terminology nationally, such as in the personally controlled electronic health records and government websites, may aid in minimizing confusion experienced by key stakeholders. Currently, owing to differences in federal, state, and territory health funding across Australia, variability exists in eligibility, based on age, for health services. A young person can therefore be ineligible to receive services in the state in which they reside, despite being eligible to receive the same services in a tertiary centre located in another jurisdiction, which may also be geo- graphically closer. Such variability may lead to confusion experienced by young people, parents, or carers when accessing services, or by health practitioners when referring individuals to their nearest tertiary centre. Age differences may also affect researchers when recruiting participants into studies.

Health practitioners, researchers, and policy makers need to be aware of the ambiguous paediatric terminology within the Australian health and health-education context. Using consistent paediatric terms with an age range when communicating with other health professionals, researchers, and policy makers, as well as with young people, parents, or carers, will aid in reducing confusion to maximize health-care delivery and research translation. The unique characteristics of Australian paediatric terminology support the definitions 'infant: 0 to $<1$ year', 'early childhood: 1 year to $<5$ years', 'child: 5 years to $<13$ years', and 'young person: 13 years to $<22$ years' as a starting point for use within Australian health and health-education contexts. The innovative method of identifying and analysing publically accessible paediatric terminology can be used to explore paediatric terminology in other nations before international standards can be developed.

\section{ACKNOWLEDGEMENTS}

The authors have stated that they had no interests that might be perceived as posing a conflict or bias.

\section{SUPPORTING INFORMATION}

The following additional material may be found online:

Appendix S1. Specific search strategies for Australian health and health-education websites.

\section{REFERENCES}

1. Kahn MG, Bailey LC, Forrest CB, et al. Building a common pediatric research terminology for accelerating child health research. Pediatrics 2014; 133: 516-25.

2. Williams K, Thomson D, Seto I, et al. Standard 6: age groups for pediatric trials. Pediatrics 2012; 129(Suppl. 3): S153-60.

3. Contopoulos-Ioannidis DG, Seto I, Hamm MP, et al. Empirical evaluation of age groups and age-subgroup analyses in pediatric randomized trials and pediatric meta-analyses. Pediatrics 2012; 129(Suppl. 3): S16184.

4. Eunice Kennedy Shriver National Institute of Child Health and Human Development 2013 [updated 29 May]. Efforts to Harmonize Pediatric Terminology. National Institutes of Health, 2013a. http://www.nichd.nih.gov/health/clinicalresearch/clinical-researchers/terminology/Pages/index.aspx (accessed 17 August 2014).

5. Australian Bureau of Statistics. Using Children and Youth Statistics 2007 [updated 25 June 2013]. http:// www.abs.gov.au/websitedbs/c311215.nsf/web/Children+ and+Youth+Statistics+-+Using+Children+and+Youth+ Statistics (accessed 29 August 2014).
6. Macquarie Dictionary: Australia's National Dictionary Online (6th edition). North Ridge, NSW: Macquarie Library, 2013b. http://www.macquariedictionary.com.au/ (accessed 17 August 2014).

7. Spriggs MP, Gillam LH. Consent in paediatric research: an evaluation of the guidance provided in the 2007 NHMRC National statement on ethical conduct in human research. Med f Aust 2008; 188: 360-2.

8. Jeyendra A, Rajadurai J, Chanmugam J, et al. Australian general practitioners' perspectives on their role in wellchild health care. BMC Fam Pract 2013; 14: 2.

9. Sanci LA, Sawyer SM, Kang MS, et al. Confidential health care for adolescents: reconciling clinical evidence with family values. Med 7 Aust 2005; 183: $410-4$.

10. Australian Law Reform Commission. For Your Information: Australia Privacy Law and Practice. Report No. 108. Australian Law Reform Commission, 2008. http:// www.alrc.gov.au/publications/68.\%20Decision\%20Making $\% 20$ by $\% 20$ and $\% 20$ for $\% 20$ Individuals $\% 20$ Under\% 20the \%20Age \%20of\%2018/capacity-and-health-info (accessed 18 August 2014).
11. Sinha IP, Altman DG, Beresford MW, et al. Standard 5: selection, measurement, and reporting of outcomes in clinical trials in children. Pediatrics 2012; 129(Suppl. 3): S146-52.

12. Klassen TP, Hartling L, Craig JC, Offringa M. Children are not just small adults: the urgent need for highquality trial evidence in children. PLoS Med 2008; 5: 1180-2.

13. Usher WT. Gold Coast general practitioners' recommendations of health websites to their patients. Med 7 Aust 2007; 187: 82-3.

14. Gauld R, Williams S. Use of the Internet for health information: a study of Australians and New Zealanders. Inform Health Soc Care 2009; 34: 149-58.

15. Kripalani S, LeFevre F, Phillips CO, et al. Deficits in communication and information transfer between hospitalbased and primary care physicians: implications for patient safety and continuity of care. 7AMA 2007; 297: 831-41.

16. Ambresin AE, Bennett K, Patton GC, et al. Assessment of youth-friendly health care: a systematic review of indicators drawn from young people's perspectives. 7 Adolesc Health 2013; 52: 670-81. 
17. Hansen DL, Derry HA, Resnick PJ, Richardson CR. Adolescents searching for health information on the Internet: an observational study. 7 Med Internet Res 2003; 5: e25.

18. Williams N, Mughal S, Blair M. 'Is my child developing normally?': a critical review of web-based resources for parents. Dev Med Child Neurol 2008; 50: 893-7.

19. Booth ML, Bernard D, Quine S, et al. Access to health care among Australian adolescents young people's perspectives and their sociodemographic distribution. 7 Adolesc Health 2004; 34: 97-103.

20. Lokker N, Sanders L, Perrin EM, et al. Parental misinterpretations of over-the-counter pediatric cough and cold medication labels. Pediatrics 2009; 123: 1464-71.

21. National Cancer Institute 2013 [updated 26 August]. NCI Thesaurus version 13.08d. http://ncit.nci.nih.gov/ ncitbrowser/pages/home.jsf?version=13.08d. (accessed 18 August 2014).

22. Jones PD, Seoane L, Deichmann R Jr, Kantrow C. Differences and similarities in the practice of medicine between Australia and the United States of America: challenges and opportunities for The University of Queensland and the Ochsner Clinical School. Ochsner 7 2011; 11: 253-8.

23. Alberani V, De Castro Pietrangeli P, Mazza AM. The use of grey literature in health sciences: a preliminary survey. Bull Med Libr Assoc 1990; 78: 358-63.

24. Luther J. GL ' 99 explores "New Frontiers in Grey Literature”. Library Hi Tech News 2000; 17: 10.

25. Boluyt N, Tjosvold L, Lefebvre C, et al. Usefulness of systematic review search strategies in finding child health systematic reviews in MEDLINE. Arch Pediatr Adolesc Med 2008; 162: 111-6.

26. Kastner M, Wilczynski NL, Walker-Dilks C, et al. Agespecific search strategies for Medline. 7 Med Internet Res 2006; 8: e25.

27. Sinha I, Jones L, Smyth RL, Williamson PR. A systematic review of studies that aim to determine which out- comes to measure in clinical trials in children. PLoS Med 2008; 5: e96.

28. National Library of Australia 2006. Preserving Access to Digital Information: Grey Literature. http://pandora.nla.gov.au/pan/10691/20110824-1153/www.nla.gov. au/padi/topics/372.html (accessed 17 August 2014).

29. Eysenbach G, Powell J, Kuss O, Sa ER. Empirical studies assessing the quality of health information for consumers on the world wide web: a systematic review. 7AMA 2002; 287: 2691-700.

30. Ansani NT, Vogt M, Henderson BA, et al. Quality of arthritis information on the Internet. Am 7 Health Syst Pharm 2005; 62: 1184-9.

31. Bernstam EV, Walji MF, Sagaram S, et al. Commonly cited website quality criteria are not effective at identifying inaccurate online information about breast cancer. Cancer 2008; 112: 1206-13.

32. Alyusuf RH, Prasad K, Abdel Satir AM, et al. Development and validation of a tool to evaluate the quality of medical education websites in pathology. 7 Pathol Inform 2013; 4: 29.

33. Kalankesh LR, New JP, Baker PG, Brass A. The languages of health in general practice electronic patient records: a Zipf's law analysis. 7 Biomed Semantics 2014; $5: 2$.

34. Ritschard G. CHAID and earlier supervised tree methods. In: McArdle J, Ritschard G, editors. Contemporary Issues in Exploratory Data Mining in the Behavioral Sciences. New York: Routledge, 2010: ???-????.

35. Bhavnani SK. Domain-specific search strategies for the effective retrieval of healthcare and shopping information. Interactive poster presented at: CHI 2002: Changing the world, changing ourselves; April 20-25; Minneapolis, Minnesota, USA; 2002: 610-1.

36. McLean R, Richards BH, Wardman JI. The effect of Web 2.0 on the future of medical practice and education: Darwikinian evolution or folksonomic revolution? Med 7 Aust 2007; 187: 174-7.
37. Van De Belt TH, Engelen LJ, Berben SA, Schoonhoven L. Definition of Health 2.0 and Medicine 2.0: a systematic review. 7 Med Internet Res 2010; 12: e18.

38. O'Reilly T 2005. What is Web 2.0. http://oreilly.com/ web2/archive/what-is-web-20.html (accessed 18 August 2014).

39. Ackland R, Spink AH, Bailey P 2008. Characteristics of .au Websites: An analysis of large-scale web crawl data from 2005. The thirteenth Australiasian world wide web conference; 2007 Jun 30-Jul 4; Charlesworth Bay, NSW. 2008 http://eprints.qut.edu.au/14470/ (accessed 17 August 2014).

40. Whienton K. Flat vs. deep website hierarchies 2013. http://www.nngroup.com/articles/flat-vs-deep-hierarchy (accessed 17 August 2014).

41. Wright A, Bates DW. Distribution of problems, medications and lab results in electronic health records: the $\mathrm{Pa}$ reto Principle at work. Appl Clin Inform 2010; 1: 32-7.

42. Sanders LM, Federico S, Klass P, et al. Literacy and child health: a systematic review. Arch Pediatr Adolesc Med 2009; 163: 131-40.

43. Kannan VD, Veazie PJ. Who avoids going to the doctor and why? Audience segmentation analysis for application of message development. Health Commun 2014; 25: $1-11$.

44. Hill DA, Delaney LM, Roncal S. A chi-square automatic interaction detection (CHAID) analysis of factors determining trauma outcomes. 7 Trauma 1997; 42: 62-6.

45. Dickens BM, Cook RJ. Adolescents and consent to treatment. Int 7 Gynecol Obstet 2005; 89: 179-84.

46. Gill D, Crawley FP, LoGiudice M, et al. Guidelines for informed consent in biomedical research involving paediatric populations as research participants. Eur 7 Pediatr 2003; 162: 455-8.

47. Australian Bureau of Statistics 2013. Schools 2013. http:// www.abs.gov.au/AUSSTATS/abs@.nsf/Lookup/4221.0 Main+Features100042013? OpenDocument (accessed 17 August 2014). 


\section{Author Query Form}

Journal: $\quad$ DMCN

Article: 12803

Dear Author,

During the copy-editing of your paper, the following queries arose. Please respond to these by marking up your proofs with the necessary changes/additions. Please write your answers on the query sheet if there is insufficient space on the page proofs. Please write clearly and follow the conventions shown on the attached corrections sheet. If returning the proof by fax do not write too close to the paper's edge. Please remember that illegible mark-ups may delay publication.

Many thanks for your assistance.

\begin{tabular}{|l|l|c|}
\hline Query reference & Query & Remarks \\
\hline 1 & $\begin{array}{l}\text { AUTHOR: Please confirm that given names (red) and surnames/family } \\
\text { names (green) have been identified correctly. }\end{array}$ & correct \\
\hline 2 & AUTHOR: Please check that authors and their affiliation is correct. & correct \\
\hline 3 & AUTHOR: Please provide the page range for reference [34]. & $48-74$ \\
\hline
\end{tabular}




\section{WILEY \\ Online Proofing System Instructions}

The Wiley Online Proofing System allows authors and proof reviewers to review PDF proofs, mark corrections, respond to queries, upload replacement figures, and submit these changes directly from the PDF proof from the locally saved file or while viewing it in your web browser.

1. For the best experience reviewing your proof in the Wiley Online Proofing System please ensure you are connected to the internet. This will allow the PDF proof to connect to the central Wiley Online Proofing System server. If you are connected to the Wiley Online Proofing System server you should see the icon with a green check mark above in the yellow banner.

2. Please review the article proof on the following pages and mark any corrections, changes, and query responses using the Annotation Tools outlined on the next 2 pages.

3. To save your proof corrections, click the "Publish Comments" button appearing above in the yellow banner. Publishing your comments saves your corrections to the Wiley Online Proofing System server. Corrections don't have to be marked in one sitting, you can publish corrections and log back in at a later time to add more before you click the "Complete Proof Review" button below.

4. If you need to supply additional or replacement files bigger than 5 Megabytes (MB) do not attach them directly to the PDF Proof, please click the "Upload Files" button to upload files:

Upload files

Click Here

5. When your proof review is complete and you are ready to submit corrections to the publisher, please click the "Complete Proof Review" button below:

\section{Complete Proof Review}

Click Here

IMPORTANT: Do not click the "Complete Proof Review" button without replying to all author queries found on the last page of your proof. Incomplete proof reviews will cause a delay in publication.

IMPORTANT: Once you click "Complete Proof Review" you will not be able to publish further corrections. 
Once you have Acrobat Reader open on your computer, click on the Comment tab at the right of the toolbar:

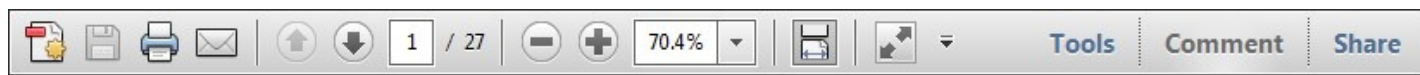

This will open up a panel down the right side of the document. The majority of tools you will use for annotating your proof will be in the Annotations section, pictured opposite. We've picked out some of these tools below:

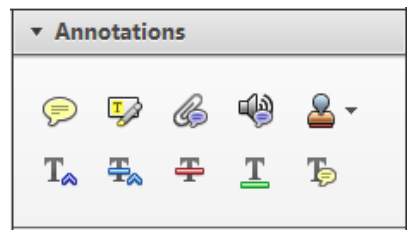

1. Replace (Ins) Tool - for replacing text.

Tistikes a line through text and opens up a text box where replacement text can be entered.

How to use it

- Highlight a word or sentence.

- Click on the Replace (Ins) icon in the Annotations section.

- Type the replacement text into the blue box that appears.

ıdard tramework for the analysis of $\mathrm{m}$ icy-Nevertheless, it also led to exog،

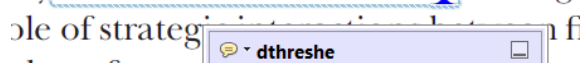
aber of comp 08/06/2011 15:58:17 $\quad$ O is that the $\mathrm{s} 1$, which led of nain compo: be level, are exc nc

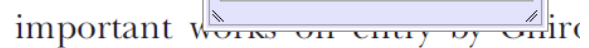
M heneforth) 1 we onen the 'hlarle $\mathrm{t}$

3. Add note to text Tool - for highlighting a section to be changed to bold or italic.

T) Highlights text in yellow and opens up a text box where comments can be entered.

How to use it

- Highlight the relevant section of text.

- Click on the Add note to text icon in the Annotations section.

- Type instruction on what should be changed regarding the text into the yellow box that appears.

namic responses of mark ups ent with the VAR evidence

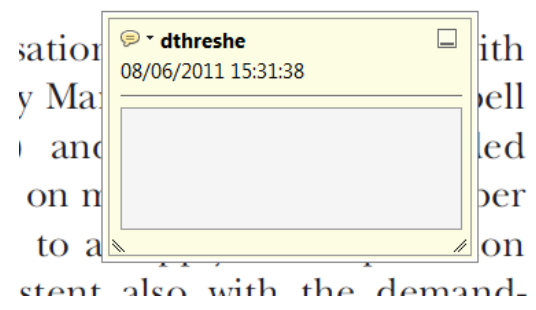

2. Strikethrough (Del) Tool - for deleting text.

T Strikes a red line through text that is to be deleted.

How to use it

- Highlight a word or sentence.

- Click on the Strikethrough (Del) icon in the Annotations section.

there is no room for extra protits al s ups are zero and the number of zet) values are not determined by Blanchard and Kiyotaki (1987), sfect competition in general equilil ts of aggregate demand and supply lassical framework assuming monol een on evorenous number of firme

4. Add sticky note Tool - for making notes at specific points in the text.

Marks a point in the proof where a comment needs to be highlighted.

How to use it

- Click on the Add sticky note icon in the Annotations section.

- Click at the point in the proof where the comment should be inserted.

- Type the comment into the yellow box that appears.

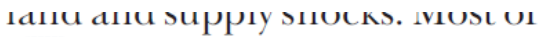

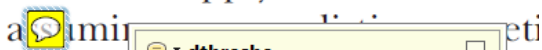

numbe $\mid \begin{aligned} & \ominus \text {-dthreshe } \\ & 08 / 06 / 2011 \text { 15:18:08 }\end{aligned}$

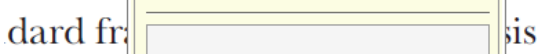

cy. Nev pa

le of st $\square$ wi

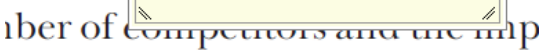

is that the structure of the secto 
5. Attach File Tool - for inserting large amounts of text or replacement figures.

Inserts an icon linking to the attached file in the appropriate place in the text.

\section{How to use it}

- Click on the Attach File icon in the Annotations section.

- Click on the proof to where you'd like the attached file to be linked.

- Select the file to be attached from your computer or network.

- Select the colour and type of icon that will appear in the proof. Click OK.

\section{E N D}

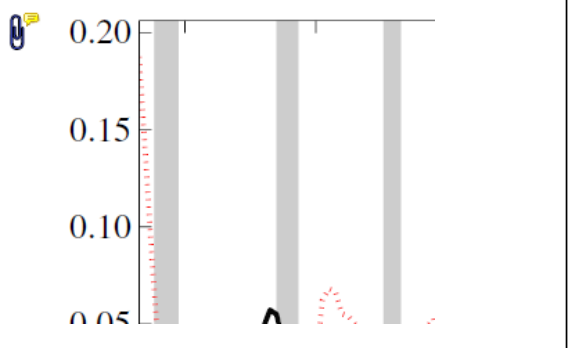

6. Drawing Markups Tools - for drawing shapes, lines and freeform annotations on proofs and commenting on these marks. Allows shapes, lines and freeform annotations to be drawn on proofs and for comment to be made on these marks.

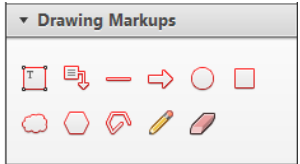

How to use it

- Click on one of the shapes in the Drawing Markups section.

- Click on the proof at the relevant point and draw the selected shape with the cursor.

- To add a comment to the drawn shape, move the cursor over the shape until an arrowhead appears.

- Double click on the shape and type any text in the red box that appears.

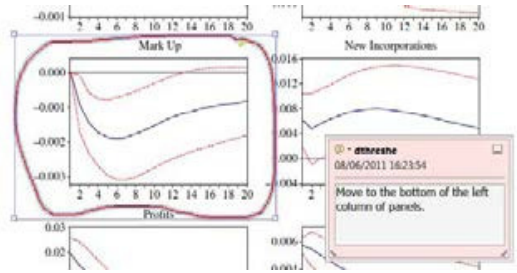

